\title{
Lecture Summaries
}

\section{The Cluniac Monastery of Paisley: a preliminary investigation}

\author{
John Malden
}

During 1990 it was decided that the site of the Cluniac Monastery of Paisley should be examined prior to the preparation of a landscaping scheme. Founded in c 1165 by Waler, the High Steward, with monks from Much Wenlock in Shropshire, the monastery was located on the bank of the River White Cart, adjacent to an ancient ford. The northernmost Cluniac House, it was raised to abbatial status in 1219, becoming one of the two Cluniac Abbeys in Britain - out of a total of 15 throughout Europe - the other being its daughter-house at Crossraguel. A wide range of documentary evidence survives for the monastery, although it is now scattered between Paisley, the National Library of Scotland, the British Library, the Bibliothèque Nationale, in Paris, and the Public Record Office of Northern Ireland, in Belfast.

The area has been cleared twice, first in 1760 to create the New Town of Paisley, and then during the earlier part of this century when the properties were bought up and handed over to Paisley Burgh on the understanding that they would be demolished and that nothing would ever be built on the site.

From newspaper reports it was known that a section of the main drain of the monastery had survived until at least the late 19 th century; efforts were made to locate its position using resistivity, magnetometry and ground-probing radar surveys: all of these were unsuccessful. Eventually, a chance remark from a member of Strathclyde Regional Council's Sewerage Department identified a hidden access-manhole. Using a robot television camera, it was found that $90 \mathrm{~m}$ of stone-lined arched tunnel existed, along with two additional access points. It was agreed that what was thought to be a thin layer of silt should be removed by suction pump, although it soon became clear that some $0.75 \mathrm{~m}$ depth of compacted material remained.

Renfrew District Council provided finance for the silt to be removed, revealing a tunnel some $2 \mathrm{~m}$ high and $1 \mathrm{~m}$ wide, with a stone-flagged floor. Some $30 \mathrm{cu} \mathrm{m}$ of silt were removed and closely examined. During the removal, large fragments of about 300 pottery vessels were found, including a complete 16 th-century chamber pot. From the examination of the silt a large quantity of pottery fragments was retrieved along with a range of small artefacts, including metal brackets, hooks, lead weights, plain glass, a gaming token, dice, tuning pegs from stringed instruments, and an ornate knife handle. Fourteen lead cloth-seals were discovered, bearing designs from London, Ulm, Arras, and Valenciennes, showing that the monks of Paisley were importing their cloth from Europe. A corroded seal-matrix, with one-third broken off, is proving difficult to identify. Fragments of slate have been recovered with examples of writing, geometric designs and music. One piece is now accepted as being the earliest recorded polyphonic music to be discovered in Scotland. Other pieces of slate have been subjected to computerized image enhancement to assist in identification. Botanical remains in the silt show not only evidence for the foods, plant dyes and medicinal plants used by the monks, but also for the first archaeological evidence to be found in the United Kingdom of the spice, mace, and remains of horse radish. 
From the documentary and archaeological evidence it appears that the drain was allowed to silt up from the first decade of the 14th century for about 30 years. From the documentary sources it is known that, during this period, Paisley had two rival abbots involved in a power struggle, during which time the fabric was allowed to fall into disrepair. It is to be hoped that full-scale excavation work on the site can be arranged to reveal more of the fourth wealthiest monastery in Scotland.

\section{The Sculptor's Cave, Covesea, Moray: from Bronze Age ossuary to Pictish shrine?}

\section{Ian A G Shepherd}

The Sculptor's Cave, Covesea, is located in sandstone cliffs between Burghead and Lossiemouth, on the southern shore of the Moray Firth. Its name comes from the series of Pictish symbols carved on its entrance wall but it owes its place in Scottish prehistory to the excavations of Miss Sylvia Benton between 1928 and 1930 (Proc Soc Antiq Scot, 69 (1930-1), 177-216).

The lecture reviewed briefly the evidence from Miss Benton's excavations and from those directed by Ian and Alexandra Shepherd in 1979 on behalf of the Scottish Development Department (Ancient Monuments) and Grampian Regional Council.

Prior to the Late Bronze Age, the interior of the cave would have been unavailable for settlement, being waterlogged. The Late Bronze Age date for the primary layer in the west entrance is taken from the piece of ring money found in it which would normally be dated to $c 700$ BC (uncal). The overlying stratified deposits, narrow bands of varying mixtures of sand, clay and charcoal, are taken to represent floor-deposits and interludes of disuse. The sequence in the east entrance is similar, with a primary occupation layer of similar matrix to that in the west entrance, this time dated to the seventh century BC (uncal) by the shaft of a swan's-neck bronze pin.

The evidence of subsistence consisted of (neonatal) cattle bones from nearly all the LBA levels, as well as sheep and goat. Small quantities of wild boar, domestic pig, hare, and roe deer were identified. Of the birds, evidence of a white-tailed sea eagle came from the primary layer in the east entrance, and the bones of puffin, razorbill, and guillemot were elsewhere. Numerous fish bones in the LBA layers represented salmon or trout, wrasse, cod, saithe, haddock, flounder, and plaice.

The remains of neonatal to very young calves indicate that the cave was occupied when the cattle were calving, presumably in the late spring. A goat mandible is from an animal killed at $3 \frac{1}{2}-5$ months; if born in early April, this would be a summer death. The large cod were more likely to have been taken offshore during the summer. This evidence is not conclusive, but it suggests use of the cave during the spring and summer, perhaps into the autumn; it does not support year-round occupation.

The excavations in 1979 recovered several lower jaws of children, incorporated in the basal deposits. It is now clear that the quantity of human bone found at Covesea by Miss Benton was considerably greater than previously realised. No fewer than 1800 human bones were found from most squares of the cave, a significant proportion being from the Bronze Age levels. We have to imagine that within the cave there was a spread of predominantly children's bones at a density of over seven bones per sq $\mathrm{m}$ and there was evidence of the deliberate removal of the skulls, either for display outside the cave, or for use elsewhere. The best parallel for Covesea is the cave at Heathery Burn, County Durham (Inventaria Archaeologica, GB 55). 
Covesea and Heathery Burn can be compared with several West European caves which also appear to have been used as ossuaries and for votive deposits in the Late Bronze Age. The best attested group lies in the Ardennes, in south-east Belgium, most notably the Trou de Han at Han sur Lesse, and the Trou de Leuve at Sinsin. At Han, the point where the River Lesse emerges from a series of limestone caverns, considerable quantities of human bones have been recovered, accompanied by an impressive array of metalwork, comprising bronze armlets, axes, swords, pendants and, most strikingly, a series of ring money interchangeable with the Covesea examples. Near the exit were seven human mandibles showing signs of decapitation. For the closest parallels for the bronzes we have to look in several directions: for the Saint-Omer-Lysel pendants to north and west France, for the ring money similarly (and to southern England/Ireland), while the other bronzes (such as the three 'proto-Hallstatt' swords) are generally considered to sit within the prevailing 'Rhine-Swiss-east France' group of the LBA IIb/IIIa.

At Covesea there was little evidence of subsequent use, indicating that the cave was not a settlement site in Pictish times. The later phases of use consisted of sterile layers of soft humic material spread in the entrance passages, material which was never consolidated by regular trampling. A range of small bronze objects - fourth-century Roman bronze coins (range AD 353-65), tweezers, and 10 ring-headed pins (one of which was silver) - was deposited inside the cave (the coins concentrating around square B4), perhaps in a single event sometime in the late fourth century, or slightly later. At least 15 Pictish symbols were carved on the walls and roof of the entrance passages, but none was found inside.

Set on a sandstone water-girt ridge, Covesea was more than a summer seaside resort for Bronze Age fishers and wildfowlers, or for strandloping Picts. It may be too rash to describe it as an early Celtic ossuary, although the parallels with the Belgium (and French) caves are suggestive; a (backward-looking) justification of such a characterization can also come from its relationship in Pictish times with the great citadel of Burghead, which, with the Early Christian site at Kinneddar, Lossiemouth, comprise a unique Pictish focus.

\section{Digging for Flint: The Den of Boddam/Buchan Ridge Gravel Project, Aberdeenshire}

\section{Alan Saville \& David Bridgland}

During the early phases of prehistoric settlement in Scotland, flakeable stone was a highly significant resource, used for the manufacture of implements essential in everyday life. The superior properties of flint made it the ideal raw material, but its availability within Scotland is generally restricted to coastal locations in the form of derived pebbles of small size. The exception is in the north-east, where terrestrial deposits, known as the Buchan Ridge Gravels, contain frequent and substantial flint cobbles. These deposits occur on the higher ground in an area about $13 \mathrm{~km}$ across, running inland from near Boddam, just to the south of Peterhead in Aberdeenshire.

The Buchan flint deposits have aroused interest since their scientific recognition in the early 19 th century, and controversy still exists about their age and formation. One location in particular, the Den of Boddam, attracted attention because of the bumps and hollows - features which we now recognize as pits and spoilheaps - still visible on the surface. 
No archaeological excavation was undertaken at Boddam, but at the western end of the Buchan Ridge Gravel, G S Graham-Smith excavated two trenches at Skelmuir Hill in 1918. This site, now levelled by cultivation, had retained surface hollows, similar to those at Den of Boddam, up to the end of the 19th century. Graham-Smith concluded that the site was a flint workshop, but remained vague about the date or purpose of the hollows he encountered.

A new research project was established in 1991 by the National Museums of Scotland to investigate the archaeology of the Buchan Ridge Gravel. Initial work focused on the Den of Boddam from 1991 to 1993; in 1993 test-pits were made elsewhere on the gravels; and in 1994 excavation took place at Skelmuir Hill. At the Den of Boddam, steep unploughed slopes retain the surface evidence of some 458 hollows, but many more former extraction pits exist beneath the surrounding ploughed fields. Excavation concentrated on the west side of the Den where some $300 \mathrm{sq} \mathrm{m}$ were examined - well below a $1 \%$ sample of the total mined area - including the investigation of four pits. Extraction of the flint in prehistory was shown to have been achieved by bell-pitting. The soil and glacial till were dug through to reach the underlying flint-rich gravel, to depths up to $4.4 \mathrm{~m}$. At Skelmuir Hill, excavation concentrated on re-opening the cuttings made by Graham-Smith in 1918. Some $250 \mathrm{sq} \mathrm{m}$ were machine-stripped, revealing a superficially similar pattern to Boddam: buried peaty hollows marking the existence of former quarry pits. The evidence from this sample suggests that the hilltop at Skelmuir is covered with intersecting pits.

Flint waste is present by the ton at both these industrial sites. The hundreds of thousands of pieces of flint observed during excavations are chiefly the outcome of primary processing, in which the cobbles have been broken open in a kind of quality-testing procedure; what remains is the unwanted, rejected waste. This primary processing was achieved either by hand-held knapping, resulting in simple platform cores, or by bipolar flaking, where the flint was placed on an anvil before being struck by the hammer. The anvils are a highly distinctive by-product of this process.

Dating the mining activity on the Buchan Ridge Gravel is difficult. The current excavations have not yet produced any diagnostic flint artefacts, and the soils are acidic, so bone, antler, and timber objects would not survive unless burnt. Thus far, the only dating evidence has come from the radiocarbon analysis of two natural deposits, which provide an approximate bracket for the mining. An area where the buried soil was well preserved beneath upcast from extraction pits has been dated to between 3500 and 3000 cal BC. A nearby pit feature had a substantial infill of peat, which sealed flint-knapping debris. The base of the peat has been dated to between 2500 and 2000 cal BC. These dates point to the late Neolithic as the phase in which mining took place at Boddam. In Britain as a whole, mining and quarrying of lithic raw materials is a mainly Neolithic phenomenon, with a particular accentuation during the later Neolithic, as attested, for example, at Grimes Graves in Norfolk. The current project has shown that the scale of extraction in Buchan may not be that dissimilar to that on the chalk.

The Buchan flint itself is different from chalk flint, being much less reliable and not available in large enough sizes for conventional axehead manufacture. It must have been used for a variety of smaller implement types, amongst which arrowheads may well have been the most important. 


\section{The Discovery Programme: recent developments in Irish archaeological research}

Anne Lynch

A new era dawned in Irish archaeological research in 1991 when the Taoiseach, Charles Haughey, initiated the Discovery Programme. The aims are twofold: through archaeological and related research, to work towards a coherent and comprehensive picture of human life in Ireland from earliest times; and to formulate the results in ways which can be communicated to experts and to the general public.

This State recognition of the value of pure research in archaeology and the need for longterm programmes to address fundamental questions was especially welcome at a time when integrated research had been all but abandoned due to the increasing pressures of rescue and salvage archaeology. A Panel of 13 individuals, chaired by Professor George Eogan, oversees the direction of the Discovery Programme which is financed by funds from the National Lottery channelled through the National Heritage Council.

The first task undertaken by the Panel was a broad review of Irish archaeological studies covering the period from about $8000 \mathrm{BC}$ to $\mathrm{AD} 1700$. This led to the isolation of a number of major issues worthy of investigation. A recurring theme that arose from this review was the extraordinary dearth of information on many aspects of settlement in virtually every period. There was wide agreement therefore that the habitation aspects of settlement should be the primary concern of the Programme at this time. As far as general strategy was concerned, it was agreed that the Programme should begin its work by concentrating on a particular core period.

It was decided that for the first three to five years attention would be focused on the later Bronze Age and Iron Age periods (c 1200 BC-C AD 550), an era of exceptional change and development in Irish prehistory. Within this time-span, significant developments occurred in the field of metalworking (in gold, bronze and iron); long-distance exchange-networks were established with Britain and with mainland Europe, and a complex hierarchical Celtic-speaking society emerged.

Within the chosen period, the Panel instituted five quite varied projects and these have been up and running since 1992.

Dr Eoin Grogan is directing the North Munster Project which aims to identify the pattern of human settlement and to analyse the cultural, environmental and social processes represented in the settlement distribution in the study area which centres on the lower reaches of the River Shannon. A regional approach has been adopted and already the dynamics of settlement distribution and models of settlement hierarchy are beginning to emerge.

In the Ballyhoura Hills Project, Martin Doody is undertaking detailed survey and excavation of a series of potential late prehistoric sites in counties Cork and Tipperary. A Middle/Late Bronze Age settlement and ritual complex at Chancellorsland, County Tipperary, is currently the focus of intensive investigation.

As director of the Western Stone Fort Project, Claire Cotter is investigating the nature and chronology of some of the large stone forts in the west of Ireland. The forts on the Aran Islands, County Galway, have been surveyed in detail, and excavations at Dun Aonghasa have revealed the presence of an extensive Late Bronze Age settlement at the earliest stages of fort construction.

A comprehensive survey of the ceremonial sites on the Hill of Tara, County Meath, has been undertaken by Conor Newman as part of the Tara Project. The results have enabled us to develop 
theoretical models as to how the hillside developed since prehistoric times. In tandem with the archaeological survey, Dr Edel Bhreathnach is researching the documentary sources relating to Tara (which date from the seventh century onwards), and a bibliography of sources is to be published.

Finally, Dr David Weir has completed a detailed palynological study of the first millennia $\mathrm{BC} / \mathrm{AD}$ in an area of good agricultural potential in County Louth. This work has highlighted significant changes in agricultural practices with interesting implications for the social and political organization of the period.

Dissemination of the results of the Discovery Programme is of paramount importance and already two reports (The Discovery Programme: Strategies and Questions and Discovery Programme Reports: 1, Project Results 1992) are in print. These are to be followed by four major publications, including a guidebook for the Hill of Tara. Material for schools, in the form of working posters and teacher packs, are also being produced.

\section{Scotland in the Little Ice Age: the science and the poetry}

\section{Ian Morrison}

The way in which so many Scots have taken up today's popular concern over 'Global Warming' seems a bit paradoxical. Through much of our history, cooling rather than warming has been our problem. Nowadays, however, most people seem blithely unaware of just how near-run a thing it has been for us to have escaped a renewed glaciation of Scotland in recent centuries. Those who regard themselves as Friends of the Earth appear to have missed the point that by our dirty habits we may well have polluted ourselves out of the imminent onset of another episode of the Ice Age.

In terms of the planet as a whole, the phase in which we live appears as merely one of the intermissions ('interglacials') which have temporarily intervened in the Quaternary Ice Age, which has dominated most of the last two million years. In this, there have been many interglacials which have been both longer and pleasanter in their climate than the phase we are in at the moment, which seems to have passed its best over 5000 years ago. We have a relatively bland climate in Scotland at present, and there have been other favourable episodes in recent centuries too, but from the end of the Viking era (when the northern seas were less icy and favoured their voyaging) right up to Victorian times, glaciers elsewhere in the world often reasserted themselves; this late- and post-medieval phase has come to be known as the 'Little Ice Age'.

During this period, although actual glaciers did not take over Scotland, there were several times when snow built up from year to year in the corries, and as late as the 1690 s we came very close to a resumption of glaciation. With so many of the population of pre-industrial Scotland depending on subsistence agriculture, the effects of these harsher climatic phases could be grievous, and calculations suggest that the impact may have been as severe in some cases as the Black Death.

The experience of living through that kind of weather appears not only in the scientific record, but is reflected vividly in the poetry of Scotland, from the days of Gavin Douglas and William Dunbar at the court of James IV, right through to the 18th Century, when an Ayrshire lad found that the climate was better suited to life in the Excise Service, than as a ploughman - or as a mouse ... 


\title{
Map-making in Roman Scotland: from Marinus to the Military Survey
}

\author{
Gordon S Maxwell
}

This paper deals largely with the cartographic representation of North Britain by the Alexandrian geographer Ptolemy around the middle of the second century $\mathrm{AD}$, but it embraces consideration of the work of later map-makers who sought to depict Roman antiquities on regional maps of Scotland. There is a conscious acknowledgement of earlier papers on the same subject, presenting the views of Flinders Petrie and of Richmond, but part of the present stimulus is the need to harmonize the Ptolemaic data with the enormous increase of site-data stemming from recent aerial discoveries.

Mention nevertheless needs to be made of the untapped information incorporated in the surveys of such later map-makers and scholars as Pont and Adair, or Roy, whose military experience combined with a sharp eye to produce measured drawings of Roman works that still repay close scrutiny.

Past interest in Ptolemy has tended to concentrate on the problems of identifying named sites with Roman stations, or explaining the angular distortion of the northern part of the British mainland. But the 'twisting' of Scotland is merely one instance of errors which can be detected throughout his map of Britain, some of which were doubtless derived, along with geographical information, from his various sources, notably Marinus of Tyre. The study of the Ptolemaic map therefore requires a reappraisal of his working methods, and an appreciation of the mechanics of the distance-and-bearing system of site-location. In particular, examination of the basic structure of the map reveals not only measurement errors but also an apparent selection of mapping control-points, these being recognisable as coinciding with wholedegree coordinates of longitude and latitude. These points can be sub-divided, as may all Ptolemaic data, into coastal and inland points, the latter equating, significantly, with centres of high military or political importance: London, Verulamium, Catterick and, in Scotland, Newstead.

Closer analysis within this structure indicates frequent doubling or halving of measured distances between adjacent locations, which could have led to major distortions of coastal outline, if affecting the presumed control-points; such errors, which may be detected in South-West Britain, as well as in Scotland, could account for 'missing' forts or towns (poleis). However, omission of data because of rigorous selection also seems possible, such influence probably explaining a uniform density of poleis across the entire map - in England, Scotland, and even in Ireland! It is possible that this evenness hints at an early sub-division of the British map into several regional modules, traces of which are still to be found in the Ravenna Cosmography. Other basic errors include misidentifications due to early scribal slips, and the possibility that tribal areas, if related to distorted coastlines, may not safely be associated with the poleis assigned to them by Ptolemy. Such vitiation of the evidence may even survive in certain early post-Roman sources; all these sources need urgently to be reassessed. 


\section{Images and artefacts: the material culture of Jacobitism in Scotland and England, 1688-1788}

\section{Eirwen E C Nicholson}

Summary of a paper delivered at the conference, 'Jacobitism, Scotland and the Enlightenment', at the University of Aberdeen, August 1995, for which the author received a Young Fellows Bursary from the Society.

This paper took a critical look at the state of documentation and scholarly analysis of the images and three-dimensional artefacts by which the Jacobite message was articulated and disseminated in Scotland and England over the century 1688-1788.

Four essential and related problems were identified: (i) an absence of comprehensive scholarly documentation, leading to problems of authentication but also frustrating comprehensive analyses of the material; (ii) the predominance of specialist artefact-related scholarship and of sentimental antiquarianism; (iii) the way in which the absence of documentation in particular serves the interests of dealers rather than those of scholars; (iv) problems of curatorial practice and the tendency to uphold artefactual studies and antiquarianism, together with an insufficient development of the conceptual framework of 'material culture' as it might apply to Jacobite artefacts, militating against both empirical and analytical research.

The implications of these failures (for our understanding of the material culture of Jacobitism, and for the status of both the artefacts themselves and for Jacobite scholarship as this has developed in the past 25 years) were set forth in strong terms.

The paper began by introducing 'material culture' as a conceptual framework as this has been developed by cultural anthropologists. It then moved on to examine the interrelation of the four problems outlined above.

(i) The failure of documentation and authentication, and the need for an evidential base quite simply, what was made for a Jacobite market? - from which other necessary studies, of the iconography and rhetoric of those images and artefacts, can be constructed. There is a lack of scholarly reference works concerning the nature and whereabouts of surviving Jacobite images and artefacts. Such documentation would eliminate spurious and anachronistic material.

(ii) The extent to which (far more than has been the case with other types of surviving evidence for Jacobitism) research and publication in this field have too often been the product of amateurism in its negative sense: the work of collectors and connoisseurs rather than of trained scholars. The resulting literature (addressed to fellow amateurs rather than to professional historians) is usually restricted as to medium, and is preoccupied with objects as artistic creations or craft, rather than as political productions and primary historical evidence. This literature is likely to be characterized by a failure to comment on those aspects of an artefact which are of relevance to the historian (eg the number of copies feasibly in circulation, and the means of circulation), by frequent factual error, and by the continued currency of half-baked speculation (most notably with regard to the iconography of Jacobite glasses).

(iii) The commercial dimension. The ready identification by dealers and auction houses of 18 thcentury portraits as 'Prince Charles Edward Stuart' or 'Flora Macdonald'; the currency of the tag 'of possible Jacobite significance' for any glass, or any piece of china from this period that bears a rose or a thistle.

(iv) The presentation of Jacobite art and artefacts in public galleries and museums. The tendency towards a historical eclecticism; the display of genuine and later 19th-and even 20thcentury material side by side, while failing adequately to distinguish between them.

There are implications of all this for Jacobite scholarship. Images and artefacts were identified as the Achilles' heel of an otherwise substantial historical recovery and reassertion of the importance of Jacobitism to 18th-century Britain. There is a need for equivalent efforts if images and artefacts are to be more than a decorative adjunct to 'real' Jacobite scholarship. 